\title{
Effects of Different Video Modalities on Writing Achievement in Flipped English Classes
}

\author{
Duygu Umutlu \\ Bogazici University, Turkey \\ ORCID: 0000-0002-2030-2626 \\ Yavuz Akpinar \\ Bogazici University, Turkey \\ ORCID: 0000-0002-9406-3795
}

Received: 14 Feb 2020

Accepted: 7 Apr 2020

\begin{abstract}
This study investigated different modalities of videos in a flipped classroom for English writing classes in an intensive English program at a state university in Turkey. This quasi-experimental study was conducted with six experimental groups $(n=109)$ and one control group $(n=18)$. The dataset included the participants' scores of an essay pretest and two posttests, namely, recall and essay posttests. The data analysis showed that the experimental group viewing the video lecture which includes simultaneous presentation of animation and on-screen text followed by a narration in a user-paced environment outperformed the control group on the recall posttest. The groups studying the video lecture including animation with simultaneous narration and sequential on-screen text in a whole presentation and in a part-by-part presentation outperformed the control group on the essay writing posttest. In the whole presentation, participants studied all the parts of a video in a system-paced design and answered the related questions whereas participants studied each part of a video and answered the related questions in a part-by-part presentation. The paper provides a discussion and a set of recommendations on how to design flipped classrooms.
\end{abstract}

Keywords: flipped learning, flipped classroom, multimedia learning, video modalities, English as a foreign language, academic essay writing

\section{INTRODUCTION}

Blended learning, which entails combining face-to-face lectures with online and computer-based instruction, has gained popularity as flipped classroom and flipped learning in recent years. Neill and Etheridge (2008) state that the learning environment should be a flexible one such as a classroom without walls, and students can/should go beyond the traditional lecturing in these classrooms through individualized learning activities. More recently, this going beyond the traditional lecturing has been adjusted, and with advances in technology, new types of flexible learning environments have emerged: the flipped classroom. It has different names such as inverted classroom (Lage, Platt \& Treglia, 2000), flipped classroom (Bergmann \& Sams, 2007), and Learn Before Lecture (LBL) (Moravec, Williams, Aguilar-Roca, \& O'Dowd, 2010).

In flipped learning, students are expected to watch (online) lecture videos and tutorials on their own flexible schedule at home, and come to the classroom with already-gained background information, which they utilize for in-class hands-on or experimental activities and problem-solving tasks (Akçayır \& Akçayır, 2018; Szafir \& Mutlu, 2013). In this study, the flipped design was implemented in English writing classes. The 
purpose of this study was two-fold: One was to measure the effect of flipped classroom in English writing classes, and the second was to investigate the effect of different modalities of multimedia representations used in those learning materials.

\section{Flipped Classroom}

In a flipped design, short lecture videos are assigned to the students so that they can study them before coming to the class and become ready to do some related activities in class. By means of the video lectures, classroom time is devoted more to answering questions that come from students, practicing, focusing on problem sets, and getting support from the teacher in flipped learning. As a result, the traditional homework becomes schoolwork in a flipped learning environment.

Some researchers (e.g., Bergmann \& Sams, 2012; McGivney-Burelle \& Xue, 2013; Sarawagi, 2014; Talbert, 2014) claim that flipped learning can be based on Bloom's taxonomy of cognitive domains (1956). In flipped learning, while the first two phases such as remembering and understanding occur at home, the last four high-level skills such as applying, analyzing, evaluating, and creating can be utilized during in-class activity time.

In order to benefit from the flipped design most, it should be used in higher education with adolescents and adults, but not in the introductory level courses (Strayer, 2012; Tomas, Evans, Doyle, \& Skamp, 2019). The videos assigned as homework should not be too long. The optimal duration for videos is less than 15 minutes (Wan, 2014). By taking the context and the learner needs into account, when it is designed properly, flipped classes become useful, which results in more learning gain than traditional classes (Bergmann \& Sams, 2007; Moravec, Williams, Aguilar-Roca \& O’Dowd, 2010; Turan \& Akdag-Cimen, 2019).

In the studies comparing post-secondary flipped classes with traditional classes (e.g., Day \& Foley, 2006; Love, Hodge, Grandgenett \& Swift, 2012; Talbert, 2014), learning in flipped classes was found to be equal to or greater than learning in traditional classes. However, the flipped classroom has been applied mostly in computer science, economy, science and math courses up to now (e.g., Baepler, Walker, \& Driessen, 2014; Foertsch, Moses, Strikwerda, \& Litzkow, 2002; Lage, Platt \& Treglia, 2000; Sezer, 2017; Strayer, 2012). Few studies can be found in social sciences, humanity, and language classes. There is a particular scarcity of studies on the effects of flipped classroom in foreign language learning contexts (Engin, 2014).

In Wong and Chu's study (2014), the effect of flipped listening classes on speaking skills was analyzed. The study was conducted in the academic year 2013-2014 with 68 students. The students in the flipped classroom were asked to study short videos before in-class time and take online exercises. The students in the traditional classroom (control group) studied the videos in the classroom, and then did the exercises. At the end, both groups were given a post-test (including multiple-choice and fill-in-the-blanks questions) about the videos. The results show that the students in the flipped classroom performed better in speaking tasks than the ones in the traditional classroom. They also stated that studying videos before class had a positive effect on their speaking skills and they came to the class more motivated to discuss the video-related cases. Kvashnina and Martynko (2016) flipped an undergraduate English for engineering course at a university in Russia. Forty-two students participated in the study. The flipped groups had higher scores than the control group did in the final exam including listening, reading, writing, and speaking tasks, and also the participants in the flipped classes were found to have positive attitudes towards integration of technology in language classes via flipped classroom. Alhamami and Khan (2019) investigated whether flipped learning has any effects on reading achievement. 43 freshman students participated in the study at a Saudi university. No significant difference in the posttest results was found between the face-to-face and flipped classes. That is, both types of instruction are equally effective in promoting English reading skills of beginner learners (Alhamami \& Khan, 2019).

There is little research analyzing the effects of flipping in writing classes where English is a foreign language (Engin, 2014). In addition to that, up to now, only traditional classes and flipped classes have been compared, and almost no exploration regarding the design of videos has been made in the flipped classroom studies (Day \& Foley, 2006; Love, Hodge, Grandgenett, \& Swift, 2012; Talbert, 2014). There are few studies analyzing 
different video formats in flipped learning environments (Chen \& Wu, 2015). To fill these gaps in the literature, this study was conducted in intensive English writing classes and compared both the traditional classroom with flipped classrooms and flipped classrooms using varying types of videos. In this paper, traditional classroom refers to a learning environment where most of the class time is devoted to face-toface instruction mainly given by the teacher and few practice activities take place (Schmidt, 2009).

\section{Multimedia Learning}

According to Mayer (2014), multimedia learning helps students to create mental representations by presenting visual or auditory materials to learners. Mayer (2014) puts forward two goals and three types of learning outcomes of multimedia learning. The first goal of multimedia instruction is to enable learners to remember and recognize the presented material. The second goal is to let learners use what they get from the presented material in new and different situations. Retention tests are used to test the former goal, whereas transfer tests are conducted to test the latter. Three types of learning outcomes can be observed at the end of a multimedia learning process (Mayer, 2014). The first one is no learning which indicates poor retention and poor transfer. The second type is rote learning as a result of good retention, but poor transfer. The final type is meaningful learning which results in integrated knowledge due to good retention and good transfer. Meaningful learning is the intended goal of multimedia learning and instruction.

To achieve meaningful learning, some factors and design features of multimedia learning should be taken into account. There are three main assumptions or theories that can be utilized while designing multimedia learning environments. Dual Channel Assumption (Paivio, 1978) claims that human beings have two channels to process the information presented to them. One of them is visual, and the other one is auditory. Pictorial input is processed in the visual channel whereas verbal input is processed in the auditory channel. Cognitive Load Theory (Sweller, 1988) asserts that working memory has a limited capacity; thus, processing the visual or auditory input can be overloading for it. According to Sweller (1988), there are three types of cognitive load. Intrinsic load results from the nature of the material; that is, from its default complexity whereas extraneous load is caused by inappropriate instructional design. Germane load, on the other hand, is the cognitive load emerging as a result of learning effort. Therefore, the goal of multimedia learning environment design is to remove extraneous load while triggering germane load.

Taking Sweller's cognitive load theory (1988) and Paivio's dual channel assumption (1978) into consideration, Mayer (2014) suggests the cognitive theory of multimedia learning in order to make multimedia learning meaningful for learners. In his theory, Mayer (2014) suggests twelve multimedia design principles to decrease extraneous load, but to increase germane load. Three of the principles used in this study were: (1) multimedia principle which states people learn better from words and pictures than words alone, (2) redundancy principle that claims people learn better from graphs/pictures and narration rather than graphs/pictures, narration, and on-screen text, and (3) modality principle that asserts that people learn better when graphs/pictures are presented with narration rather than with on-screen text. In several previous studies (e.g., Jamet \& Le Bohec, 2007; Mayer \& Johnson, 2008; Shapiro, 2008), it was found that when multimedia learning environments are designed based on these principles, learning is enhanced. The fourth principle that was tested in this study was segmenting principle. According to this principle of Mayer (2014), people learn better when they are provided with user-paced pieces of a multimedia presentation rather than a whole, unsegmented presentation. In previous studies (e.g., Mayer \& Chandler, 2001; Mayer, Dow, \& Mayer, 2003), learners who viewed segmented or part-by-part presentations outperformed the ones who viewed whole, unsegmented presentations in transfer tests. Another aspect of the videos used in this study was videos being user-paced or system-paced. In their study, Corbalan, Kester, and Van Merriënboer (2008) found that learners' task involvement increased when the presentation was user-paced and controlled by learners.

\section{Developing Writing Skills}

According to White and Arndt (1991), writing is not a simple process that involves just spelling the words correctly and putting words together. On the contrary, writing is a process that involves high-level cognitive thinking processes. Even in their native language, people have difficulties putting their ideas together 
coherently although they have broad knowledge of language structures (Susser, 1994; White \& Arndt, 1991). When it comes to writing in a foreign and second language, the task becomes much more difficult even though writing is mostly based on cognitive processes, not language structures. Because foreign or second language learners are required to write according to different schemata of a different language which is unfamiliar to them, they engage in more challenging cognitive processes involved in writing (Susser, 1994; White, 1988). Thus, the aim of foreign or second language writing courses should be to teach students how to compose their ideas, not the specific language structures because writing a composition or an essay does not only mean producing grammatically correct sentences (Nagao, 2019; Zamel, 1976).

Language use also has a goal of conveying messages. This goal can be achieved through certain receptive skills such as reading and listening, and productive skills such as writing and speaking. These skills need to be improved in a language learning process, and multimedia design aims to enhance this process. When multimedia instruction is integrated to language learning, it becomes a part of Computer-Assisted Language Learning (CALL). Plass and Jones (2005, p. 469) define the use of multimedia to learn a language as "use of words and pictures to provide meaningful input, facilitate meaningful interaction with the target language, and elicit meaningful output."

Use of interactionist approaches in second language acquisition in CALL environments is supported (Chapelle, 2009). The first stage is the comprehensible input stage (Krashen, 1987). In a multimedia language learning environment, learners select words or pictures so that they can perceive and comprehend the input. In this stage, learners cannot produce any target language but understand it. Once the input is comprehended, it becomes intake to be integrated into learners' prior linguistic knowledge. This forms the second stage of the interactionist approach that involves interactive processing. After these two stages are completed, learners are expected to produce their comprehensible output (Richards \& Rodgers, 1986) which is the result of knowledge transfer. In CALL environments, different multimedia modalities such as visual input or auditory input are incorporated into these stages of the interactionist approach.

It can be argued that the first two phases of this approach occur outside the class in flipped writing classes through multimedia videos. Once learners comprehend the input, they come to class to produce output through hands-on activities in flipped designs. In this way, it is more possible for learners to focus on producing meaningful, coherent, and grammatical sentences while writing since more in-class time is allocated for activities and tasks that necessitate high-order thinking skills. Flipped learning in language classes can also be associated with the pedagogy "Present-Practice-Produce (PPP)" (Richards \& Rodgers, 1986). Based on the stages of this model, the present stage occurs at home while learners are studying the video lectures presenting information, and the practice and produce stages are completed in class when they are involved in tasks and activities in a flipped learning environment. Thus, implementation of the flipped design in writing classes is probable to result in better learning gain.

\section{Purpose of the Study and the Research Questions}

This study aims to examine the effect of flipped classes on students' writing achievement in an intensive English program and to investigate whether modality of flipped video lectures, including animation/diagram, narration, and on-screen text presented either simultaneously or sequentially in a system-paced or userpaced design, affects the writing achievement of students.

Accordingly, the study aimed to answer the following questions:

(i) Do flipped writing classes affect the students' writing achievement in English classes?

(ii) Does the modality of flipped video lectures affect the writing achievement of the students?

\section{METHODOLOGY}

This study employed a quasi-experimental pretest-posttest design (Cook \& Wong, 2008; Creswell, 2012). The intact pre-intermediate classes, which are equivalent of B1 in Common European Framework, in the intensive 
Table 1. Videos with Different Modalities for the Experimental Groups

\begin{tabular}{|c|c|c|}
\hline Video Type & Video Code & Video Description \\
\hline $\begin{array}{l}\text { Animated slides with simultaneous Narration followed by } \\
\text { Text in a user-paced/learner-controlled linear } \\
\text { presentation }\end{array}$ & $\mathrm{AN}+\mathrm{T}$ & $\begin{array}{l}\text { Participants could watch the } \mathrm{AN}+\mathrm{T} \text { linear video } \\
\text { presentation by clicking on the buttons to pace } \\
\text { it themselves (see Figure 1). }\end{array}$ \\
\hline $\begin{array}{l}\text { Animated slides with simultaneous Text followed by } \\
\text { Narration in a user-paced/learner-controlled linear } \\
\text { presentation }\end{array}$ & $\mathrm{AT}+\mathrm{N}$ & $\begin{array}{l}\text { Participants could watch the } \mathrm{AT}+\mathrm{N} \text { linear video } \\
\text { presentation by clicking on the buttons to pace } \\
\text { it themselves (see Figure } 2 \text { ). }\end{array}$ \\
\hline $\begin{array}{l}\text { Animated slides with simultaneous Narration followed by } \\
\text { Text in a system-pacing linear presentation }\end{array}$ & $A N+T \_W$ & $\begin{array}{l}\text { Participants watched the whole } \mathrm{AN}+\mathrm{T} \text { video, } \\
\text { and then answered related multiple-choice } \\
\text { questions (see Figure 3). }\end{array}$ \\
\hline $\begin{array}{l}\text { Animated slides with simultaneous Narration followed by } \\
\text { Text in a system-pacing part-by-part presentation }\end{array}$ & $A N+T \_P$ & $\begin{array}{l}\text { Participants answered a few of the multiple- } \\
\text { choice questions after watching each related } \\
\text { part of the AN+T video (see Figure 4). }\end{array}$ \\
\hline $\begin{array}{l}\text { Animated slides with simultaneous Narration followed by } \\
\text { Text in a completely learner-controlled presentation }\end{array}$ & $\mathrm{AN}+\mathrm{T} \_\mathrm{LC}$ & $\begin{array}{l}\text { Participants could access the AN+T video slides } \\
\text { in any preferred order (see Figure } 5 \text { ). }\end{array}$ \\
\hline $\begin{array}{l}\text { Animated slides with simultaneous Text followed by } \\
\text { Narration in a completely learner-controlled presentation }\end{array}$ & $\mathrm{AT}+\mathrm{N}_{-} \mathrm{LC}$ & $\begin{array}{l}\text { Participants could access the } A T+N \text { video slides } \\
\text { in any preferred order (see Figure } 6 \text { ). }\end{array}$ \\
\hline
\end{tabular}

Note. A set of sample video lectures can be found at https://bit.ly/2ZkCggK, only for review purposes, not for use.

English program were involved in the study through convenience sampling. That is, instructors of all preintermediate classes were interviewed, and seven of them volunteered to participate in the study. Before the intervention, a pretest including an essay question was given to all groups, and after the intervention a recall posttest and an essay posttest were conducted in all groups. While the flipped design with different modalities was the independent variable, writing achievement was the dependent variable in this study.

\section{Participants and Setting}

The participants were 127 pre-intermediate students in the intensive English program at a state university where the medium of instruction is English in Istanbul, Turkey. The participants were 18-19 years old. They were in their first year at the university. There were six experimental groups, each of which studied videos including different modalities and one control group receiving lectures in a traditional classroom. The participants in the flipped classes (experimental groups) were assigned video lectures about classification essay and asked to watch them before they came to the class. The number of participants in each experimental group ranged from 15 to 20 . The participants in the traditional classroom $(n=19)$ were provided with the same lecture content about classification essay via face-to-face instruction. The traditional class instructor presented the same content through printed materials and worksheets.

\section{Data Collection Procedures and Materials}

The intervention was conducted during the classification essay unit in which students learned to write fiveparagraph essays categorizing people, concepts, or objects based on a principle or criterion. Before conducting the study, an approval was taken from the Institutional Review Board and Ethics Committee of the university where the study was conducted. Accordingly, informed consents from all participants were taken.

Before the intervention, an essay pretest was given to all groups. The pretest essay topic was types of TV programs because the intervention was conducted for the classification essay type, and the participants were asked to write the classification essay in fifty minutes. The prompt given for the pretest essay was "Write $a$ classification essay about types of TV Programs. You have 50 minutes. You may use the categories given as follows or you can write about you own points: (a) Entertainment programs, (b) TV series, (c) News programs, (d) Sports programs, and (d) Documentaries."

Following the pretest, a slide-based video lecture was assigned for home viewing to the experimental groups, with each group receiving the lecture in a different format. Six versions of the video lecture were prepared by the first researcher (see Table 1 and Umutlu (2016) for details). 
Table 2. Data Collection Procedures

\begin{tabular}{|c|c|c|}
\hline & Traditional Classroom/ Control Group & Flipped Classroom/ Experimental Groups \\
\hline Day 1 & $\begin{array}{l}\text { (The lesson plan was given to the instructor) } \\
\text { Informed consent forms were collected from } \\
\text { the participants. }\end{array}$ & $\begin{array}{l}\text { (The lesson plans were given to the instructors.) } \\
\text { Informed consent forms were collected from the participants. }\end{array}$ \\
\hline Day 2 & The essay pretest was administered. & The essay pretest was administered. \\
\hline Days 3-8 & & $\begin{array}{l}\text { Video lectures related to structures used in the classification } \\
\text { essay and the organization of the essay were assigned to the } \\
\text { participants to study at home (outside class time). }\end{array}$ \\
\hline Day 9 & $\begin{array}{l}\text { Video lecture content through hard-copy } \\
\text { materials was covered by the class instructor. }\end{array}$ & \\
\hline Day 10 & Recall posttest was administered. & Recall posttest was administered. \\
\hline Day 11-16 & $\begin{array}{l}\text { Activities related to classification essay were } \\
\text { covered in the class. }\end{array}$ & $\begin{array}{l}\text { Activities related to classification essay were covered in the class. } \\
\text { Participants wrote one practice essay in class. }\end{array}$ \\
\hline Day 17 & Posttest (Essay Writing) & Posttest (Essay Writing) \\
\hline
\end{tabular}

All of the video lectures in this study were approximately 18-20 minutes. All video lectures were prepared by the first researcher on Articulate Storyline, an authoring environment to create instructional materials. Each lecture included the same content, and the content was presented to the students in three parts: What is Classification? Organization of Classification Essay, and Useful Classification Language Structures. While the participants in the flipped classes viewed the lecture videos at home, the traditional class students received the same instruction given by their instructor in a traditional classroom setting. In the six experimental groups, the structure of writing classes was changed. That is, students in those classes were asked to allocate their out-of-class time to study the instruction in the video lectures. Therefore, the structure of classes was different for both the students and the teachers in those groups. The students were required to watch the video lectures so that they became ready for the class. The instructors changed the design of their writing lessons since they were able to spend more time on practice essay writing in the class. Although the amount of instruction given to the students was same with its amount in the traditional class, the time spent studying and understanding the instruction was distributed for the experimental groups, which is the core pillar of flipped designs (see Table 2).

A day after the lecture viewing or hearing, students in all groups took a 12-question multiple-choice recall test (see Figure 7). Aligning with the content presented in the videos and in the traditional lecture, this recall test has content validity. A sample essay analysis activity and two categorization exercises were completed in all classes. In the sample essay analysis activity, students in all groups analyzed the structure of a classification essay and discussed the structures used in it. In the categorization exercises, students in all groups were asked to categorize two topics: cars and sports. As a final posttest for the unit, all participants wrote a classification essay which was about movie types. The prompt given for this essay was: "Write classification essay about types of movies. You have 50 minutes. You may use the prompts given below or you can write about you own points: (a) Action movies, (b) Romantic movies, (c) Horror films, (d) Science-fiction movies, and (e) Animated movies."

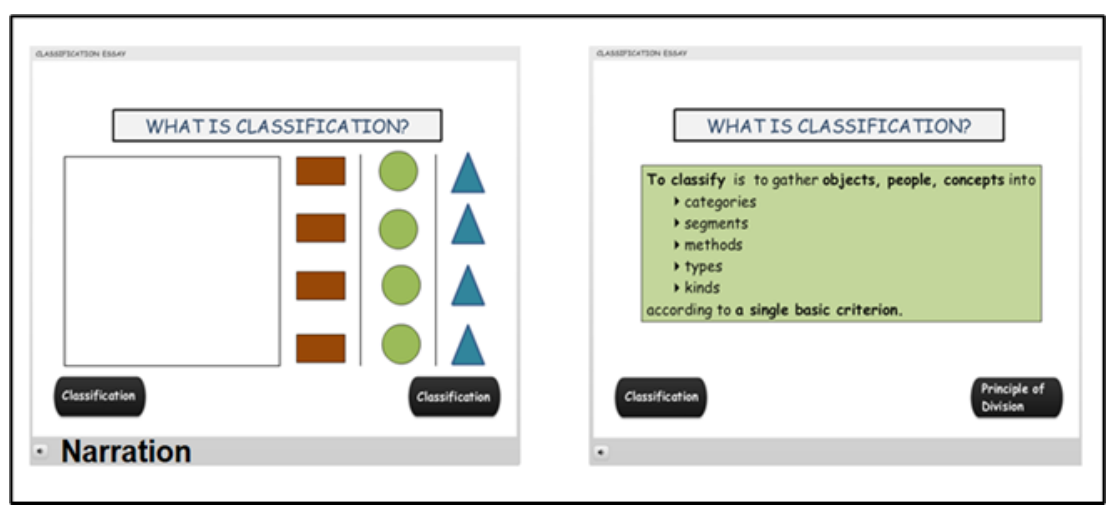

Figure 1. Sample screenshots of $\mathrm{AN}+\mathrm{T}$ 


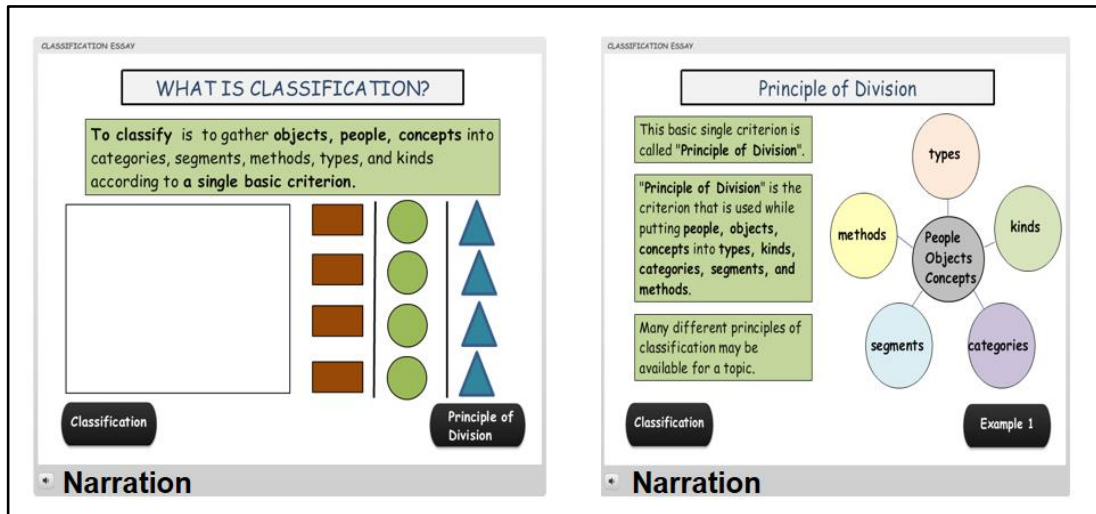

Figure 2. Sample screenshots of $A T+N$

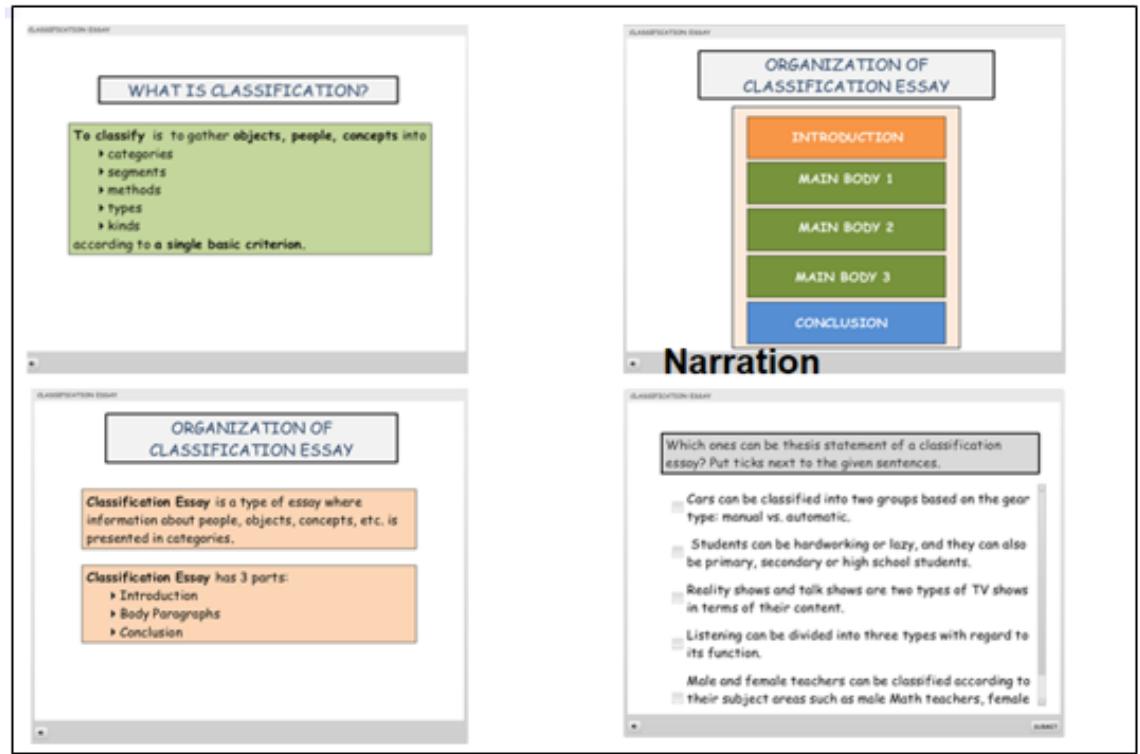

Figure 3. Sample screenshots of AN+T_W

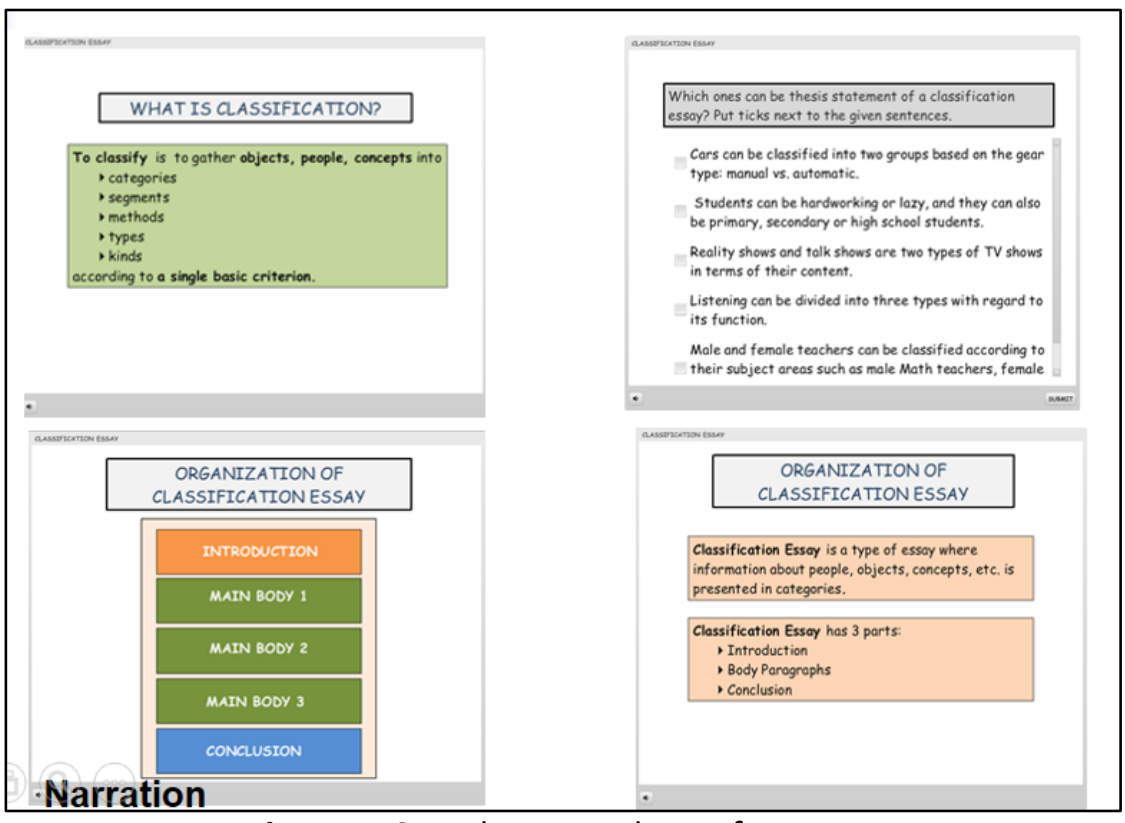

Figure 4. Sample screenshots of AN+T_P 


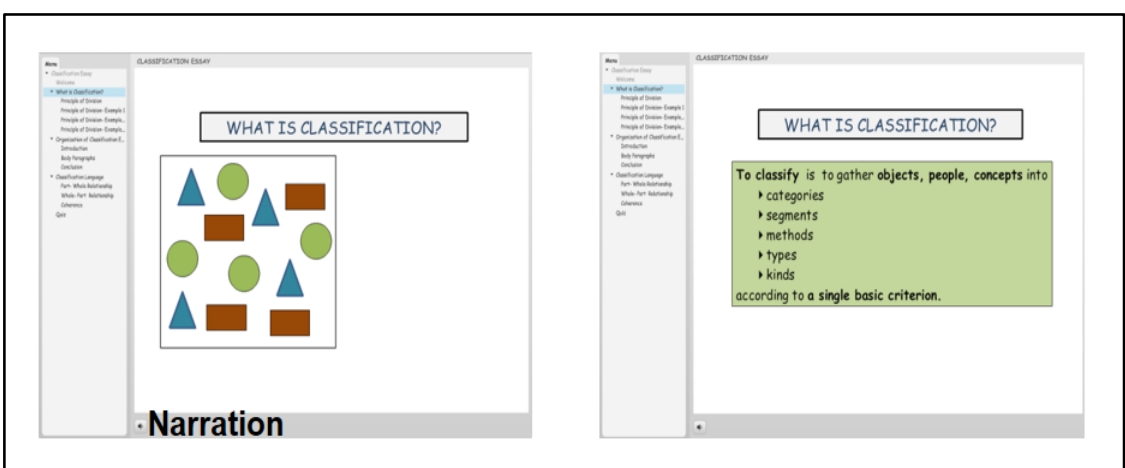

Figure 5. Sample screenshots of $A N+T_{-} L C$

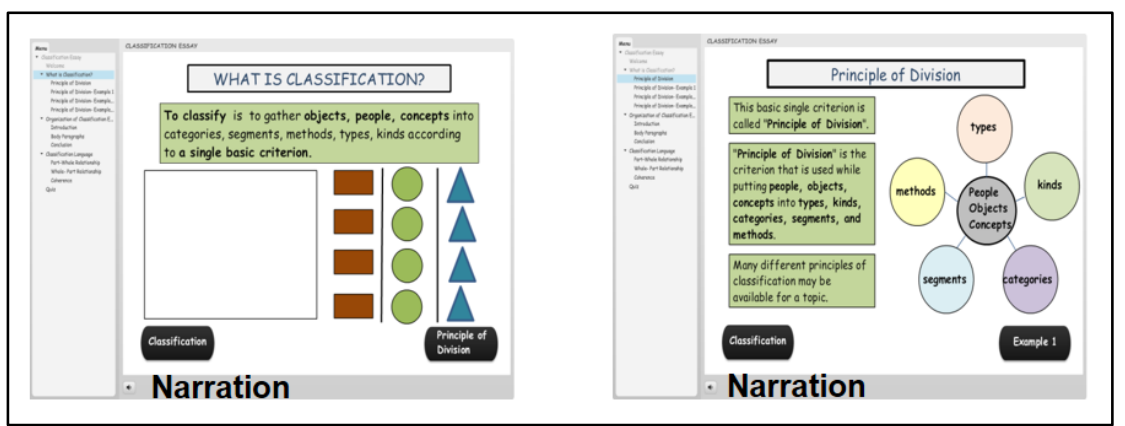

Figure 6. Sample screenshots of AT+N_LC

\footnotetext{
1) Where can you find the items below in a classification essay? Write "I" for introduction, "MB" for main body, and " $\mathrm{C}$ " for conclusion.

Explanation of each category

Thesis statement

Summary of the main ideas

Principle of division

Introduction of the topic

Restatement of the thesis statement

2) Which one can't be the thesis statement of a classification essay?

a. Cars can be classified based on the fuel type.

b. What friendship means changes from person to person.

c. Based on where they can be done, activities are classified into two categories.

d. Social media websites can be categorized with respect to their functions
}

3) Which one is not an appropriate thesis statement for a classification essay? a. Students can be categorized in terms of their achievement: low-achievers and highachievers.

b. Geometrical shapes can be categorized based on the number of their sides

c. Shops can be classified with respect to their sizes and what they sell.

d. Computers can be categorized in terms of their processors.

Cross out the category that is NOT related.

4) Animals: sea animals / wild animals / land animals / sky animals

5) Meals: breakfast / dinner/high-fat / lunch

6) Schools: private schools / primary schools / secondary schools / high schools

Figure 7. Sample questions from the recall test

\section{Data Analysis}

The questions in the recall posttest (Cronbach's $\alpha=.78$ ) had only one correct answer, and the total score was 25 points. Under blind review, the pretest and posttest essays were checked by two markers based on a holistic standardized rubric which includes five bands: very good $=20$, good $=16$, satisfactory $=12$. doubtful $=10$, unsatisfactory $=8$, and poor $=4$ (see Appendix A). Cohen's kappa coefficient for the pretest was .64, and it was .88 for the essay posttest. 
Table 3. Descriptive Statistics of Each Group

\begin{tabular}{lccccccc}
\hline Intervention Types & \multicolumn{3}{c}{ Essay Pretest } & \multicolumn{2}{c}{ Recall Posttest } & \multicolumn{2}{c}{ Essay Posttest } \\
\hline & $\mathrm{n}$ & Mean & SD & Mean & SD & Mean & SD \\
AN+T & 15 & 5.0 & 1.79 & 21.6 & 3.37 & 11.0 & 2.36 \\
AT+N & 18 & 4.8 & 1.67 & 22.7 & 1.87 & 11.1 & 1.29 \\
AN+T_W & 20 & 5.3 & 1.30 & 21.7 & 2.65 & 12.3 & 2.43 \\
AN+T_P & 17 & 4.6 & 1.36 & 20.4 & 2.42 & 11.7 & 1.92 \\
AN+T_LC & 21 & 4.9 & 1.49 & 21.0 & 2.98 & 11.0 & 1.04 \\
AT+N_LC & 18 & 4.1 & 0.47 & 20.9 & 3.28 & 11.0 & 1.58 \\
Traditional Lecture & 18 & 5.1 & 2.05 & 19.7 & 2.29 & 9.3 & 2.89 \\
\hline
\end{tabular}

After the normality and homogeneity of the pretest data were checked, a parametric statistical test to compare more than two means (Field, 2013) on the pretest was selected: Analysis of Variance (ANOVA). The normality and homogeneity of the posttest data were also checked. To examine the effects of different modalities of flipped videos on the recall and essay writing posttests separately in the six groups, one ANOVA test for each posttest was conducted as its assumptions were met in the dataset.

\section{Results}

The pretest and posttest data were homogenous and normally distributed, and the descriptive statistics of the dataset are provided (Table 3 ). Based on ANOVA test results, all groups were equal in terms of the pretest scores since there was no significant difference among the groups $(F(6,120)=1.27, p=0.27)$. For the research question 1 , the test results showed that all flipped groups got higher scores than the traditional class both on the recall and essay posttests although the difference was not statistically significant for all the experimental groups.

As for the research question 2, ANOVA tests revealed a significant difference among the recall posttest scores of the groups $(F(6,120)=2.33, p=0.04)$. TukeyHSD post hoc test indicated that there was a significant difference between the AT+N group and the control group on the recall posttest $(p=0.02, d=1.43)$. That is, when the animated slides containing on-screen text were followed by narration, learners scored higher on the recall test, indicating this type of video may be better for recall and rote learning (Mayer, 2014). ANOVA tests also indicated that there is a significant difference in the essay posttest scores of the groups $(F(6,120)$ $=3.63, p=.002$ ). TukeyHSD post hoc test indicated that both groups viewing the system-paced videos $\mathrm{AN}+\mathrm{T}+\mathrm{W}$ and AN+T_P outperformed the traditional class on the essay posttest (both $p<.05, d=1.12$ and $d=$ 0.97 respectively), indicating that this type of video may promote deep learning and transfer. This result also suggests that whether the video was presented as a whole or part-by-part did not affect the essay writing performance of the participants in those two groups. It can be concluded that modality played a bigger role than the presentation style did. In addition, no significant difference was found when flipped designs (experimental groups) were compared with each other.

\section{Discussion}

This study showed that the flipped classes viewing the $A T+N$ video type outperformed the traditional classroom in the recall posttest. Contrary to our original hypothesis, these results suggested that viewing animated slides with simultaneous text highlighting key words, followed by a more elaborate narration enhances recall although this video format was expected to cause cognitive load on the visual channel (Sweller, 1988). This finding does not comply with the dual channel theory (Paivio, 1986) or the cognitive load theory (Sweller, 1988), which assert that human beings have two channels - visual and auditory- to process input and that animation/diagram and on-screen text should not be presented together in order to avoid the cognitive load in the visual channel respectively. This finding does not align with the modality principle (Mayer, 2014) in multimedia learning which states that pictures/graphs/ diagrams should be presented with narration rather than on-screen text to offload the cognitive load in the visual channel, either. Additionally, it seems to be violating the redundancy principle which states that diagram, on-screen text, and narration should not be presented to learners at the same time; however, Moreno and Mayer (2002) argue 
that when a third modality, which can be either visual or auditory, is presented sequentially, it does not result in any redundancy effect. By contrast, Kalyuga, Chandler, and Sweller (1999) point out that presenting too many visual elements such as diagrams and on-screen text overburdens the visual channel of learners; thus, it results in split attention because learners need to pay attention to all visual elements at the same time and the working memory does not allow this since it has a limited capacity. It is also accepted that one of the ways to eliminate the split attention effect is to design the visual elements spatially close to each other so that learners are not required to search for the related visual items, which also complies with the principle of spatial contiguity in multimedia learning (Kalyuga, Chandler, \& Sweller, 1999; Mayer, 2014). In this study, as all related visual elements were placed close to each other in all intervention types, the participants studying the $A T+N$ intervention type might not have had any problems in terms of the split attention.

The fact that the group viewing the AT+N type, which presents animation (diagram) and text simultaneously, and the narration follows them, got higher scores than the control group receiving the traditional lecture, which was most probably a synchronous combination of the text on the board and the instructor's explanation, in the recall posttest can be explained with the nature of the question types in the recall posttest. The recall posttest included matching, odd-one-out, and fill-in-the blank (by choosing the correct given words from a box) questions. That is, while answering the questions in the recall posttest, the participants were required only to recognize and recall the words or the structures presented to them in the video lectures. Therefore, it is plausible to infer that when a diagram is presented together with on-screen text, it awakes the learner's attention as the on-screen text in this study is regarded as the key words for the following narration. To clarify, the onscreen text in the videos might have the role of signaling (Mayer, 2014) and giving clues about the input content in the narration. Later, when a more comprehensive narration followed the key words on the screen, the participants could revise the on-screen keywords, consolidate the input, and expand it as the narration included more details than the keywords on the screen. And, all of this process might enhance rote learning, and therefore, recall and recognition. On the other hand, the other group viewing the same video format in a completely-learner-controlled environment did not get as high scores as the outperforming group on the recall test probably because participants got lost in the presentation, reported by a few of the participants informally.

Additionally, the groups receiving $A N+T_{-} W$ and $A N+T_{-} P$ intervention types got higher scores than the traditional class did in the essay posttest. In these outperforming groups, animation and narration were presented simultaneously, and then they were followed by on-screen text. This type of design is consistent with the dual channel assumption (Paivio, 1986), the cognitive load theory (Sweller, 1988), and the modality principle (Mayer, 2014). According to the results of the essay posttest, it can be concluded that when the animation and the narration are presented simultaneously, and then these animation and narration are followed by the on-screen text, it helps learners to transfer their knowledge into a production task and to be engaged in deep learning. These intervention types may seem to be violating the redundancy principle since it presented diagram, narration, and on-screen text to the learners. However, since the on-screen text was presented sequentially in these two video lecture types ( $A N+T_{-} W$ and $A N+T_{-} P$ ) in this study, the redundancy effect was eliminated (Moreno \& Mayer, 2002). The groups which watched the video types AN+T_W and $\mathrm{AN}+\mathrm{T}$ _P were able to transfer their conceptual knowledge into a production task more successfully than the control group. The essay writing posttest was accepted as the production task in this study because essay writing is a demanding process that requires putting many language-related components such as grammar and vocabulary together in order to make or produce meaningful and grammatical sentences (White \& Arndt, 1991). As a result, it can be claimed that when the multimedia learning environments are designed according to the theories and assumptions, they are more likely to trigger meaningful learning, which is the ultimate goal of multimedia learning (Mayer, 2014).

\section{CONCLUSION}

To our knowledge, this study was one of the first studies that investigated different video types that include several modalities in a flipped learning environment for English as a foreign language. Up to now, flipped designs have been implemented mostly in science, technology, engineering, and math (STEM) courses 
(Foertsch, Moses, Strikwerda \& Litzkow, 2002; Lage, Platt \& Treglia, 2000; Baepler, Walker \& Driessen, 2014; Strayer, 2012). Also, in the flipped classroom studies so far, the traditional classroom and flipped classroom have generally been compared (Love, Hodge, Grandgenett \& Swift, 2012; Talbert, 2014). That is, there is little research on comparing flipped designs involving video lectures with different modalities in language classes. Addressing these gaps in the literature, this study was conducted in English language classes and compared both the traditional classroom with flipped classrooms and flipped classrooms with each other.

In this study, the effects of the flipped design and of different video modalities on essay writing achievement in English were examined in a quasi-experimental design. The six experimental groups were assigned video lectures about classification essay during their out-of-class time. The same content was delivered by the instructor in the control group. After this lecturing, all groups took the recall posttest and completed relevant writing exercises and tasks in class. at the end of the study, all the participants completed the essay posttest. The findings from the recall posttest point out that in a multimedia instruction if animation and on-screen text are presented simultaneously and followed by narration, it may strengthen the memory and so enhance recall. As for the essay writing posttest, it was found that the groups watching the AN+T_W and AN+T_P videos outperformed the control group. That is, the participants in those groups were able to transfer their conceptual knowledge into a production task better. Therefore, it is tenable to argue that when an instruction in a video lecture is designed in harmony with the principles of the cognitive theory of multimedia learning (Mayer, 2014), it triggers knowledge transfer.

\section{Limitations}

This study might guide teachers, language educators, and instructional designers who plan to flip their courses; however, there were limitations to the study which should not be ignored. The results should be considered cautiously because the sample size was relatively small. The number of participants in each group ranged from 15 to 20. The sample was also drawn from a specific context (the intensive English program at a state university where the medium of instruction is English in Turkey), and the materials prepared by that university's curriculum committee were used in the study. The external validity-generalizability of the results to the population- of the study is relatively low. All of the video lectures were prepared by the researcher. However, the activities in the traditional (control) and flipped (experimental) classes were conducted by 7 different instructors, one of whom was the first researcher. As the teaching style of instructors is difficult to standardize, this may decrease the internal validity of the study. Detailed lesson plans for writing classes were given to the instructors in order to keep the variance at minimum. No eye movement tracking system could be used in the study, which resulted in difficulties in examining the route the groups followed and analyzing its effects on posttest scores. Because of time constraints, a training session on how to progress in the computer-based video lessons could not be offered to the participants.

\section{Further Research}

As for future research, the number of participants should be increased, and if duration of future studies gets longer, it will become more possible to give a training session to participants. A similar study can be conducted on a different sample having different characteristics. The materials used in this study should be adapted for use at other universities so that the external validity of the study may increase. Either eyemovement tracking or screen-recording should be implemented so that the route learners follow can be detected easily. Lastly, if it is possible, all class activities should be done by the same instructor.

\section{ACKNOWLEDGEMENTS}

We would like to thank the instructors of seven pre-intermediate classes who volunteered to participate in the study for making conducting the study possible. 


\section{REFERENCES}

Akçayır, G., \& Akçayır, M. (2018). The flipped classroom: A review of its advantages and challenges. Computers \& Education, 126, 334-345. https://doi.org/10.1016/j.compedu.2018.07.021

Alhamami, M., \& Khan, M. R. (2019). Effectiveness of flipped language learning classrooms and students' perspectives. Journal on English as a Foreign Language (JEFL), 9(1), 71-86. https://doi.org/10.23971/jefl.v9i1.1046

Baepler, P., Walker, J. D., \& Driessen, M., (2014). It's not about seat time: Blending, flipping, and efficiency in active learning classrooms. Computers \& Education, 78, 227-236. https://doi.org/10.1016/ j.compedu.2014.06.006

Bergmann, J., \& Sams, A. (2012). Flip your classroom: Reach every student in every class every day. USA: International Society for Technology in Education.

Bloom, B. S. (1956). Taxonomy of educational objectives handbook 1: Cognitive domain. New York: Longman.

Chapelle, C. A. (2009). The relationship between second language acquisition theory and computer-assisted language learning. The Modern Language Journal, 93, 741-753. https://doi.org/10.1111/j.15404781.2009.00970.x

Chen, C. M., \& Wu, C. H. (2015). Effects of different video lecture types on sustained attention, emotion, cognitive load, and learning performance. Computers \& Education, 80, 108-121. https://doi.org/10.1016/j.compedu.2014.08.015

Corbalan, G., Kester, L., \& Van Merriënboer, J. J. (2008). Selecting learning tasks: Effects of adaptation and shared control on learning efficiency and task involvement. Contemporary Educational Psychology, 33(4), 733-756. https://doi.org/10.1016/j.cedpsych.2008.02.003

Cook, T., \& Wong, V. (2008). Better quasi-experimental practice. In P. Alasuutari, L. Bickman, \& J. Brannen (Eds.), The Sage handbook of social research methods (pp. 134-164). London: Sage.

Creswell, J. W. (2012). Educational research: Planning, conducting, and evaluating quantitative and qualitative research ( $4^{\text {th }}$ ed.). Upper Saddle River, NJ: Prentice Hall.

Day, J. A., \& Foley, J. D. (2006). Evaluating a web lecture intervention in a human-computer interaction course. IEEE Transactions on Education, 49(4), 420-431. https://doi.org/10.1109/TE.2006.879792

Engin, M. (2014). Extending the flipped classroom model: Developing second language writing skills through student-created digital videos. Journal of the Scholarship of Teaching and Learning, 14(5), 12-26. https://doi.org/10.14434/josotlv14i5.12829

Field, A. (2013). Discovering statistics using IBM SPSS statistics. Thousand Oaks, CA: Sage.

Foertsch, J., Moses, G., Strikwerda, J., \& Litzkow, M. (2002). Reversing the lecture/homework paradigm using eTEACH web-based streaming video software. Journal of Engineering Education, 91(3), 267-274. https://doi.org/10.1002/j.2168-9830.2002.tb00703.x

Hao, Y. (2016). Exploring undergraduates' perspectives and flipped learning readiness in their flipped classrooms. Computers in Human Behavior, 59, 82-92. https://doi.org/10.1016/j.chb.2016.01.03

Jamet, E., \& Le Bohec, O. (2007). The effect of redundant text in multimedia instruction. Contemporary Educational Psychology, 32(4), 588-598. https://doi.org/10.1016/j.cedpsych.2006.07.001

Krashen, S. D. (1987). Principles and practice in second language acquisition. Upper Saddle River, NJ: Prentice Hall. 
Kvashnina, O. S., \& Martynko, E. A. (2016). Analyzing the potential of flipped classroom in ESL teaching. International Journal of Emerging Technologies in Learning, 11(03), 71-73. https://doi.org/10.3991/ijet.v11i03.5309

Lage, M., Platt, G., \& Treglia, M. (2000). Inverting the classroom: A gateway to creating an inclusive learning environment, Journal of Economic Education, 31(1), 30-43. https://doi.org/10.2307/1183338

Lander, B., \& Kuramoto, T. (2013). Development of the autonomous learner through blended learning, Saga University institutional repository, 29, 165-176. Retrieved from http://portal.dl.sagau.ac.jp/bitstream/123456789/120861/1/bruce_201303.pdf

Love, B., Hodge, A., Grandgenett, N., \& Swift, A. W. (2014). Student learning and perceptions in a flipped linear algebra course. International Journal of Mathematical Education in Science and Technology. 45(3), 317-324. https://doi.org/10.1080/0020739X.2013.822582

Mayer, R. E. (2001). Multimedia learning (1 ${ }^{\text {st }}$ ed.) New York: Cambridge University Press. https://doi.org/10.1017/CBO9781139164603

Mayer, R. E. (2014). Cognitive theory of multimedia learning. In R. E. Mayer (Ed.), The Cambridge handbook of multimedia learning (pp. 43-71). Cambridge University Press. https://doi.org/10.1017/ CB09781139547369

Mayer, R. E., \& Chandler, P. (2001). When learning is just a click away: Does simple user interaction foster deeper understanding of multimedia messages? Journal of Educational Psychology, 93, 390-397. https://doi.org/10.1037/0022-0663.93.2.390

Mayer, R. E., Dow, G. T., \& Mayer, S. (2003). Multimedia learning in an interactive self-explaining environment: What works in the design of agent-based microworlds? Journal of Educational Psychology, 95, 806-813. https://doi.org/10.1037/0022-0663.95.4.806

Mayer, R. E., \& Johnson, C. I. (2008). Revising the redundancy principle in multimedia learning. Journal of Educational Psychology, 100(2), 380-386. https://doi.org/10.1037/0022-0663.100.2.380

McGivney-Burelle, J., \& Xue, F. (2013) Flipping calculus, PRIMUS: Problems, Resources, and Issues in Mathematics Undergraduate Studies, 23(5), 77-486. https://doi.org/10.1080/10511970.2012.757571

Moravec, M., Williams, A., Aguilar-Roca, N., \& O’Dowd, D. K. (2010). Learn before lecture: A strategy that improves learning outcomes in a large introductory biology class. CBE-Life Sciences Education. 9, 473481. https://doi.org/10.1187/cbe.10-04-0063

Nagao, A. (2019). The SFL genre-based approach to writing in EFL contexts. Asian-Pacific Journal of Second and Foreign Language Education, 4(1), 6. https://doi.org/10.1186/s40862-019-0069-3

Neill, S., \& Etheridge, R. (2008). Flexible learning spaces: The integration of pedagogy, physical design, and instructional technology. Marketing Education Review, 18(1), 47-53. https://doi.org/10.1080/10528008.2008.11489024

Paivio, A. (1978). A dual coding approach to perception and cognition. In H. L. Pick \& E. Saltzman (Eds.) Modes of Perceiving and Processing Information (pp. 39-51). Mahwah, NJ: Lawrence Erlbaum Associates.

Plass, J. L., \& Jones, L. (2005). Multimedia learning in second language acquisition. In R. E. Mayer (Ed.), The Cambridge handbook of multimedia learning (pp. 467-488). New York: Cambridge University Press. https://doi.org/10.1017/СBO9780511816819

Raimes, A. (1983). Techniques in teaching writing. New York, USA: Oxford University Press

Richards, J. C., \& Rodgers, T. S. (1986). Approaches and methods in language teaching. UK: Cambridge University Press. 
Sarawagi, N. (2014). A flipped CS0 classroom: Applying Bloom's taxonomy to algorithmic thinking. Journal of Computing Sciences in Colleges. 29(6), 21-28. Retrieved from https://dl.acm.org/doi/abs/10.5555/2602724.2602731

Schmidt, S. W. (2009). Understanding the online learner. In V. C. X. Wang (Ed.), Handbook of research on elearning applications for career and technical education: Technologies for vocational training (pp. 482494). IGI Global. https://doi.org/10.4018/978-1-60566-739-3

Sezer, B. (2017). The effectiveness of a technology-enhanced flipped science classroom. Journal of Educational Computing Research, 55(4), 471-494. https://doi.org/10.1177/0735633116671325

Shapiro, A. M. (2008). Hypermedia design as learner scaffolding. Educational Technology Research and Development, 56(1), 29-44. https://doi.org/10.1007/s11423-007-9063-4

Strayer, J. F. (2012). How learning in an inverted classroom influences cooperation, innovation and task orientation. Learning Environments Research. 15(2), 171-193. https://doi.org/10.1007/s10984-0129108-4

Susser, B. (1994). Process approaches in ESL/EFL writing instruction. Journal of Second Language Writing, 3(1), 31-47. https://doi.org/10.1016/1060-3743(94)90004-3

Sun, J. C. Y., \& Wu, Y. T. (2016). Analysis of Learning Achievement and Teacher-Student Interactions in Flipped and Conventional Classrooms. The International Review of Research in Open and Distributed Learning, 17(1), 79-99. https://doi.org/10.19173/irrodl.v17i1.2116

Sweller, J. (1988). Cognitive load during problem solving: Effects on learning. Cognitive Science, 12(2), 257285. https://doi.org/10.1016/0364-0213(88)90023-7

Szafir, D., \& Mutlu, B. (2013). ARTFuL: Adaptive review technology for flipped learning. Proceedings of the SIGCHI Conference on Human Factors in Computing Systems (pp. 1001-1010). New York: ACM. https://doi.org/10.1145/2470654.2466128

Talbert, R. (2014). Inverting the linear algebra classroom, PRIMUS: Problems, Resources, and Issues in Mathematics Undergraduate Studies, 24(5), 361-374. https://doi.org/10.1080/10511970.2014. 883457

Tomas, L., Evans, N., Doyle, T., \& Skamp, K. (2019). Are first year students ready for a flipped classroom? A case for a flipped learning continuum. International Journal of Educational Technology in Higher Education, 16(1), 5. https://doi.org/10.1186/s41239-019-0135-4

Turan, Z., \& Akdag-Cimen, B. (2019). Flipped classroom in English language teaching: a systematic review. Computer Assisted Language Learning, 1-17. https://doi.org/10.1080/09588221.2019.1584117

Umutlu, D. (2016). Effects of different video modalities on writing achievement in flipped English classes (Unpublished master thesis). Bogazici University, Turkey.

Wan, N. (2014). Flipping: The science classroom exploring merits, issues and pedagogy. Teaching Science. 60(3), 16-27. Retrieved from https://search.informit.com.au/documentSummary; dn= 679293416794804;res=IELHSS

White, R. V. (1988). Introduction. In P. C. Robinson (Ed.), Academic writing: Process and product (pp. 4-16). London: Modern English Publications.

White, R., \& Arndt, V. (1991). Process writing. London: Longman.

Wong, K., \& Chu, D. W. (2014). Is the flipped classroom model effective in the perspectives of students' perceptions and benefits? In S. K. S. Cheung, J. Fong, J. Zhang, R. Kwan, \& L. F. Kwok (Eds.), Hybrid Learning. Theory and Practice (pp. 93-104). Chennai: Springer International Publishing. https://doi.org/10.1007/978-3-319-08961-4 
Zamel, V. (1976). Teaching composition in the ESL classroom: What we can learn from research in the teaching of English. TESOL Quarterly, 10(1), 67-76. https://doi.org/10.2307/3585940

\section{APPENDIX A}

\section{Rubric for Essay Marking}

VERY GOOD (20) The language might not be without errors, yet the target language and vocabulary is used correctly almost without exception. The writer may exhibit a high degree of adequacy in using structures that are specific to the classification (are/can be classified/categorized/divided into types/categories/groups/classes, fall into, belong to, fit into, fall under, and a kind/type/part of). All of these structures are used correctly. The writing has a clear organizational structure, presenting each category in separate paragraphs. The paragraphs have inner coherence with clear main ideas, substantial support, and elaboration. In the thesis statement, the writer expresses the categories or types that are to be explained in main body paragraphs and principle of division.

GOOD (16) The language is marked with a high degree of adequacy in using the target language and low overall frequency of errors. When the writer attempts more sophisticated discussion, there may be some errors in more complex structures, but there is no interference with meaning. The target vocabulary is used mostly correctly. The writer uses some sentence structures and vocabulary items that are specific to the classification essay (are/can be classified/categorized/divided into types/categories/groups/classes, fall into, belong to, fit into, fall under, and a kind/type/part of). Most of these structures are used correctly. The task is well-developed; ideas are supported with more than adequate support and elaboration and are linked logically in a coherent and meaningful way. The writing has a clear organizational structure, presenting each category in separate paragraphs. In the thesis statement, the writer expresses the categories or types that are to be explained in main body paragraphs and principle of division.

SATISFACTORY (12) The language is mostly simple with few attempts at complex structures (relative and adverbial clauses). There may be some errors in the target structures; however, most are used correctly. Errors in complex structures, less frequent gerund-infinitive forms, and articles which do not impede meaning should be treated with tolerance. Target vocabulary appears adequate and is used and spelled mostly correctly. Although most of the sentences may be simple, there should be some variety of grammatical structures and vocabulary items that are specific to the classification essay (are/can be classified/categorized/divided into types/categories/groups/classes, fall into, belong to, fit into, fall under, and a kind/type/part of). The task is developed adequately with some supporting ideas and elaboration of points. The writing has an adequate organizational structure with connected ideas by presenting each category in separate paragraphs. The reader does not experience difficulties in reading the text. In the thesis statement, the writer expresses the categories or types that are to be explained in main body paragraphs, but the principle of division may be missing.

DOUBTFUL (10) The language is simple and marked with errors in target structures although most errors do not impede meaning. Target vocabulary is mostly used correctly with some errors in collocation and word forms. There is limited usage of some grammatical structures and vocabulary items that are specific to the classification essay (are/can be classified/categorized/divided into types/categories/groups/classes, fall into, belong to, fit into, fall under, and a kind/type/part of). The task is developed adequately and the text is generally coherent; however the writer may not always be able to sustain relevant explanation and exemplification. The writer deviates from the main goal of the classification essay which is "giving information related to categories or types". The reader may experience difficulties in reading the text at a few points in terms of language inadequacy and incoherent organization of ideas. In the thesis statement, the writer expresses the categories or types that are to be explained in main body paragraphs, but the principle of division may be missing. 
UNSATISFACTORY (8) The language is below satisfactory level with re-occurring or frequent errors in target structures and frequent omission and/or incorrect usage of prepositions; frequent word choice/form and collocation errors. There might be a few sentence fragments and errors in some linking devices. The writer is generally able to handle basic SVO structure. There is very little usage of some grammatical structures and vocabulary items that are specific to the classification essay (are/can be classified/categorized/divided into types / categories / groups / classes, fall into, belong to, fit into, fall under, and a kind/type/part of). Errors may seriously interfere with meaning at points. The writing may have some surface organization. However, the ideas may not be developed adequately and supported with enough related examples. Each category is not presented in separate paragraphs. The text may read like a list or the writer cannot establish coherence mostly due to language inability. In the thesis statement, the writer expresses the categories or types that are to be explained in main body paragraphs, but the principle of division may be missing.

POOR (4) The language is marked with serious and very frequent errors in target structures: incorrect usage of discourse markers; frequent omission and/or incorrect usage of prepositions; frequent word choice/form and collocation errors. There is NO usage of some grammatical structures and vocabulary items that are specific to the classification essay (are/can be classified/categorized/divided into types/categories/groups/classes, fall into, belong to, fit into, fall under, and a kind/type/part of). Meaning is seriously disrupted. Many sentences are incomprehensible. The text may read like a list of sentences rather than a paragraph as coherence is seriously disrupted due to the inability of the writer to express him/herself. Each category is not presented in separate paragraphs. A text of only a few short sentences or which is off-topic can only receive this score. In the thesis statement, the writer does not the categories or types that are to be explained in main body paragraphs, and there is no principle of division expressed in the thesis statement.

Correspondence: Duygu Umutlu, Bogazici University, Turkey. E-mail: duygu.umutlu@boun.edu.tr 